\title{
Future Pedagogy Teachers Readiness Formation in Dual-Oriented Education
}

\author{
Aitenova Elmira, Ibraimova Leskul, Smanova Alua, Sultanbek Malik, Beknazarov Zhambyl \\ and Shalabayeva Laura*
}

Abay KAZNPU, Almaty, Kazakhstan

\begin{abstract}
The socio-economic development of society puts forward new requirements for the teacher of training: he must be competent, educated, informed, have developed thinking. The professionalism of future teachers of training is of priority importance, and its formation is a necessary condition for the intensification of education.

The scientific search for a solution to the problem of the formation of professionalism among future teachers of training is aimed at resolving the contradictions between:

- the need of society for training specialists with a high level of professionalism and an insufficient level of their professional training; the need for personnel with a high> level of professionalism, and the undeveloped process of forming the professionalism of teachers of training at a university; the practical need for the purposeful development of the professionalism of future teachers and the existing conditions for organizing their professional development in an engineering and pedagogical university; the expediency of creating a developmental space and the existing traditional approach to the development of professionalism among future teachers of training at a university.

This research aims to analyze future pedagogy teachers' readiness formation in dual-oriented education.

It is possible to resolve these contradictions based on scientific support for the integration process of development and formation of the personality of the future teacher.

With regard to the topic of the research, we are talking about rethinking the goals and social essence of the training process.

In this paper, we have analyzed the training programmes offered to the teachers, surveying the effects and benefits of professional advancement on creating new knowledge and improving the quality of teaching. The survey results have verified the main hypothesis regarding the effect of professional readiness development in raising the quality of teaching, but they have not verified a completely auxiliary hypothesis that views (considers) as a mechanism to meet the professional development needs of teachers.
\end{abstract}

Keywords: Professional, training, teachers, Kazakhstan, dual education.

\section{INTRODUCTION}

The role and importance of life-long learning as part of a teacher's qualification is unquestionable, in particular in terms of the teachers' personal and professional development, as well as in promoting the school image, improving teacher performance, and enhancing the quality of teaching. Education is still going through a process of transition. Every day new reforms are being introduced. Most of these efforts, such as the new competence-based Curriculum Framework, focus on developing education in general; others are more specific and aim, for instance, at improving teachers' professional readiness development. The latter is a very sensitive and critically important area that requires attention and commitment. In this regard, the Ministry of Education, in collaboration with various non-profit, governmental and international organizations, has organized numerous professional training for teachers.

*Address correspondence to this author at the Kazakh State National University of Al-Farabi, Almaty, Kazakhstan; Tel: +77073851878;

E-mail: zhanat_2006@mail.ru
The peculiarities of the social functions and professional activities of future pedagogy teachers readiness determine the particular complexity and increased importance of the formation of professionalism. Therefore, for this professional group, the problem of the formation of professionalism is especially relevant.

The problem of the formation of professionalism is considered not in the aggregate of measures for training, not in the development of additional forms of education, but in the restructuring of the training system based on professional, technological, systemic, personality-oriented approaches [1].

There is a need to search for new approaches to solving the problem of the formation of professionalism in future pedagogy teachers readiness at a university. Scientific studies and publications on these issues in the theory and practice of education show how complex and multifaceted this problem is. In the pedagogical and psychological-pedagogical literature, there is a huge amount of research to improve the level of professionalism of students. 
The main task of a pedagogical university in modern conditions is the preparation of a teacher-researcher, highly professional, spiritually rich and moral person. A special place in this process is the updating of the content of education and training technologies. Without this, it is impossible to give the training of the future teacher a leading character.

The quality of the professional development of a teacher is largely determined by the nature of the content of instruction. The content of the training should cover a wide range of issues related to all areas and directions of pedagogical education. The teaching of any subject should be carried out in the context of the future profession of a student as a way of generalizing the knowledge, abilities, and skills acquired by him [2].

The professionalism of future pedagogy teachers readiness as a phenomenon of training is an integrative quality of a personality that develops in the logic of changing stages and characterizes the teacher's readiness to carry out professional activities in various fields (industry, psychological and pedagogical training, training in the working profession). The model of professionalism of teachers of training is structured by components (axiological, operational, informational); elements (personal, social, functional, technological) and types of professional and pedagogical activities (educational and professional, research, educational and design, organizational and technological, production and technological).

The theoretical and methodological basis of the research was the theory of: systems V.G. Afanasyev, J.I. von Bertalanffy, I.V. Blauberg, E.G. Yudin; activity (B.G. Ananiev, P.Ya. Galperin, C.J. Rubinstein and personally oriented E.F. Zeer, I.S. Yakimanskaya approaches in education; pedagogical integration M.N.Berulava pedagogical modelling A.F. Amend, A.U. Vardanyan. The formation of professional competence V.A. Slastenin, N.N. Tulkibaeva, pedagogical experiment (J. Glass, D. Campbell, J. Stanley. The research was carried out using a set of theoretical and empirical methods.

This process proves the achievement of goals during the formation of professional skills by means of set of exercises presented in the form of an model, which consists of components which is arranged in pedagogical activity. The pedagogical practice based on the model ensures the consistency and integrity of the process. The priority in formation of knowledge and skills are orientationted to the dominant sphere of the professional activity which is called teacher of training or in other way we call it active mastering of professionalism [3].

Purpose of the paper is to conduct a research to the available teacher professional readiness development programmes and look into teachers' perspectives and reflection on these programmes, as well as the InService Teacher Qualification programme that has been attended by most of the teachers. In other words, the paper aims to see what is the difference between training programmes and the In-Service Teacher Qualification programme, and to reflect on the impact professional development is having in increasing the quality of teaching.

From the study of literature, it is clear that despite the differing opinions regarding the history of lifelong education, the importance of professional readiness development of teachers is one of the key elements of Lifelong learning and adult education that affects teachers' work performance. In a way, unlike in ancient times, when learning was referred to as a necessity for survival, in more modern times terms "lifelong education" and "Adult Education" have increasingly been associated with quality of teaching and changing classrooms teaching and learning. But the question arises, whether there are sufficient programs available for professional readiness development, or if it is considered any form of professional development, necessary and important for each age and category of teachers?

\section{METHODS}

In this paper, we have used a quantitative and qualitative approach and the literature review, statistical analysis and interview techniques. The statistical analyses are a representation of the survey conducted with the teachers of the actual In-Service Teacher Qualification programme. The survey involved 50 attendees of the program, from different educational establishments in Kazakhstan. From the total number of the attendees, 20 or $40 \%$ are female and 30 or $60 \%$ male. The questionnaire contains in total of 6 questions. Quantitative research findings in this paper are the results of the research questionnaire. Furthermore, the interviews were also conducted with school managements, to get the real reflection directly from the school. They were asked to receive their views on the need for teacher professional readiness 
development, and in regards to the impact of the training, especially in regards to the impact of the InService Teacher Qualification programme in raising the quality of teaching. The Interview protocol contained a total of 7 questions. The above-mentioned research approach was used to verify the hypotheses, concerning the effects and the role of professional readiness development of teachers, in improving the quality of teaching and the role of the In-Service Teacher Qualification programme in meeting the professional readiness development needs of teachers.

\section{RESULTS AND DISCUSSION}

The reliability and validity of the research results are identified according to the statistical processing and mathematical calculations. The research results are based not only on the questionnaire but also observations and interviews. The results were gathered by wide testing and were obtained in the practice of educational institutions, using the methods of mathematical statistics.

The questionnaire conducted with the In-Service Teacher Qualification programme attendees, most of whom have been previously following the training programmes mentioned above, was composed of a combination of open-ended and closed factual questions. The questionnaire was designed to verify the attitude of the attendees, about the impact of professional readiness development and In-Service Teacher Qualification programme in raising the quality of teaching.
Attendance of professional readiness development training: To the question regarding attendance of professional development training, as it can be seen from the table, training that teachers have followed, are: Step by step, student-centred teaching, training for the new curriculum, Inclusion, Reading and writing for critical thinking, psychosocial training, training for student evaluation - summative and formative assessment, Basic Education programme etc. It is clearly noticed higher participation of teachers in training programmes. The reason that several teachers are not involved in these training programs may be associated with the reflection of the differences between teachers within the school, relying on only several teachers, or because of the apathy - disinterest of teachers appointed to attend training programs. When looking at the importance of teacher professional readiness development, as well as organizing various training programs, at the international level, seeing motivation for lifelong learning, as important components to the success of teachers in their work with pupils (according to the authors dealing with this issue), there is no doubt that is done on organizing numerous training programs, but also on motivating teachers to attend this training, linking this directly with increased the quality in the classroom. Such a thing regarding teachers motivation, not even happen at the national level. On the other hand, adult education, it is also important at the local level.

Experimental testing of the developed models and the process of future pedagogy teachers readiness formation among future teachers at the university was

Table 1: Samples of Questions

\begin{tabular}{|c|c|c|c|}
\hline Questions & Yes & No & No answer \\
\hline $\begin{array}{l}\text { 2. Have you had a chance earlier to undergo a training programme for professional readiness } \\
\text { development? }\end{array}$ & $68 \%$ & $26 \%$ & $6 \%$ \\
\hline $\begin{array}{l}\text { 3. Do you think that professional readiness development (considered that should continue } \\
\text { throughout life), is useful for possession of new knowledge and for raising the quality of work? }\end{array}$ & $90 \%$ & $7 \%$ & $3 \%$ \\
\hline 6. Should the program continue? & $68 \%$ & $22 \%$ & $0 \%$ \\
\hline
\end{tabular}

Table 2: Samples of Questions

\begin{tabular}{|c|c|c|c|c|c|c|}
\hline Questions & 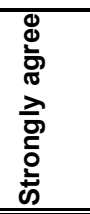 & ষ্ّ & $\begin{array}{l}\bar{\pi} \\
\stackrel{5}{5} \\
\mathbf{2}\end{array}$ & 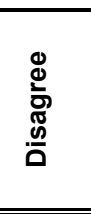 & 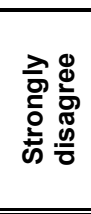 & 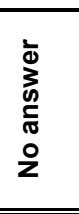 \\
\hline $\begin{array}{l}\text { 4. Does the Teacher Qualification programme provides, raising the } \\
\text { qualifications of teachers and increase the quality of teaching? }\end{array}$ & $48 \%$ & $28 \%$ & $0 \%$ & $6 \%$ & $0 \%$ & $18 \%$ \\
\hline
\end{tabular}


carried out based on the identified stages of training at the university (industry, psychological and pedagogical training and training in the working profession).

The results of the ascertaining experiment indicate that students understand the meaning and role of professionalism in modern conditions, are interested in the possibilities of forming future pedagogy teachers readiness, and imagine what properties it should have[4].

To conduct a formative experiment, the author's modular training course "Formation of future pedagogy teachers readiness ", consisting of five modules, was developed. This course is one of the effective means of increasing the level of the basic and professional culture of the future pedagogy teachers readiness, and this, in turn, is an essential qualitative stage on the path of reforming engineering and pedagogical education.

The performance indicators have been developed at each stage of professional training: the formation of educational and professional, educational and design, organizational and technological and production and technological competencies [5].

It is proved that the pedagogical practice based on the suggested methodology and set of tasks presented in this research.

The effectiveness of the proposed model of the formation of future pedagogy teachers readiness at a university has been proved, which is confirmed by the increased level of formation of professional competencies [6].

During the research authors identified the essence of professionalism of teachers training, which includes an integrative quality of a personality that is being developped in the logic of changing stages and characterizes the teacher's readiness to carry out professional activities in various educational spheres.

The formation of professionalism of a teacher of training at a university is considered not only as of the production and appropriation of new knowledge, ideas, values, personal meanings, but also as the disclosure of the essential forces, activity abilities of students, their capabilities for the competent and responsible solution of professional tasks, creating the preconditions for the continuous professional development of the personality of the future teacher of training at the university [7].
As the study has shown, the formation and development of professionalism of a teacher of training include the following elements: personal, social, functional.

Table 3: Professiogram Future Teacher of Training

\begin{tabular}{|c|c|}
\hline $\begin{array}{c}\text { personal aspect } \\
\text { professional } \\
\text { growth }\end{array}$ & $\begin{array}{c}\text { development of personality traits } \\
\text { the actualization of knowledge, skills and } \\
\text { abilities in the subject }\end{array}$ \\
\hline functional & of productivity of his activities \\
\hline technological & $\begin{array}{c}\text { development of advanced special } \\
\text { technologies }\end{array}$ \\
\hline social & mastering the art of communicating \\
\hline
\end{tabular}

The conducted theoretical analysis of the process of formation of professionalism as a social phenomenon shows that a future teacher of training at a university should have general cultural and professional competencies, ready for continuous professional growth, social and professional mobility.

The study revealed the need to use the modelling method to improve further the process of professional training of future specialists [8].

The basis for modeling the system of practical training of students from pedagogy faculties has different requirements for their personal developments and enhancement of professional skills during pedagogical activities in becoming a specialist. They should remember of the following: being systemic, using wide range of activity in teaching, apply integrative-modular approaches, as well as principles of consistency, continuity, and functional completeness, and be aware of the principle ofunity of theory and practice [9].

A model of professionalism of teachers of training has been developed, which is structured by components, axiological, operational, informational); elements of personal, social, functional, technological) and types of professional and pedagogical activities (educational and professional, research, educational and design, organizational and technological, production and technological).

External factors (socio-economic conditions for the development of society, public organizations, family, socio-cultural institutions) and internal factors (value orientations, needs and abilities of the teacher's personality), influencing the process of forming 
professionalism among future teachers of training, have been identified [10].

A represented process in this research proves that readiness of students to fulfill their profession demands from them to teach in a proper way, and have good command of knowledge because when they have knowledge not only of their subject but also possess the ability to manage the classroom in the activity, it will bring to better outcomes of the students professional skills, also they should know the different methodological approaches for effective teaching. All components mentioned in methodology brings to the better results of the students and give them better understanding of teaching skills [11].

\section{CONCLUSION}

Regarding the organization of training for professional readiness development and the possibility of attending these training, the research conducted with teachers (who have attended professional development programmes, and also the In-Service Teacher Qualification programme) shows that it has developed a relatively large number of training programmes. These training programmes primarily target innovative and up-to-date practices, including changes in teaching methodology, using new methods and techniques that focus on student-centred teaching, activation of students' critical thinking and so on [12].

The issue of the importance of professional readiness development on gaining new knowledge and in raising the quality of teaching is considered a necessity of time, because of the dynamic development of technology, and which should occur at any stage and throughout life. At this point, regarding the positive effect of teacher professional readiness development in increasing quality, the main hypothesis of the paper is verified. This happens through gaining new knowledge through the use of new methodologies in the learning process, improving teacher performance in the classroom, encouraging students' critical and logical thinking towards full and attentive understanding, as well as the application of competency-based assessment approach. However, at the national level, it is evident the lack of teachers motivation for professional development. Values of the In-Service Teacher Qualification programme as an element of lifelong learning are incontestable in terms of meeting the needs for professional development. But the organization of continuous training programmes is obligatory, because of the need to be in line with rapid changes that are occurring every day in the education area. The weakness of this program mainly belongs to several older teachers, considering this qualification programme as needless for teachers of older ages [13].

An important issue that is worth mentioning is that most of the attendees of the programme consider attending courses in the programme are considered beneficial only as a requirement to maintain the workplace, and not as really needed for their professional development.

The research results lead to the view that as training programmes, as well as the In-Service Teacher Qualification programme, help to update knowledge, but training programmes are basic mechanism, for the advancement of teaching performance.

Finally, we may conclude that professional development has a direct impact on the careers of teachers. This impact relates to the fulfilment of the criteria for reforming the educational system, among other licensing criteria, as well as the changes in the system of teachers' salaries.

\section{ACKNOWLEDGEMENT}

None.

\section{REFERENCES}

[1] Belyaeva AP. Integrative theory and practice of multileve continuous professional education. St. Petersburg: Institute of Vocational Education of the Russian Academy of Education, 2002

[2] Yu G, Tatur M. Higher. School., 1989; 143: 106.

[3] Budik IB. Development of professionally significant qualities of a future specialist in the context of the formation of key competencies. Additional education. 2001; 3: 52-54.

[4] Vardanyan YuV. Development of a student as a subject of mastering professional competence. Vardanyan YuV, Savinova TV, Yashkova AN. SPb., 2003; p. 97.

[5] Vvedensky VN. Modeling the professional competence of a teacher. Pedagogy 2003; 10: 51-55.

[6] Gusev VA. The problem of design and implementation of the system of multilevel professional-pedagogical education Education and Science. Izv. Ural. Branch Rao 2004; 3: 3542.

[7] Duranov ME Management of professional education of a future specialist in higher education (socio-cultural aspect). Chelyabinsk: ChGAKI, 2006; p. 337.

[8] Zimnyaya IA. Key competences - a new paradigm of the result of education. Higher education today 2003; 5: 34-42.

[9] Lapshova AV. The essence and structure of professionalism of a higher school teacher. Bulletin of the Vyatka State Humanitarian University 2009; 3: 67-70.

[10] Pedagogical science and its methodology in the context of the present: Sat. scientific. Art. Ed. Kraevsky VV, Polonsky VM. -M., 2001; p. 445. 
[11] Bicaj, Arberore, Treska, Tomi, PY - 2014/11/01, The Effect of Teacher Professional Development. Academic Journal of Interdisciplinary Studies.

[12] Barrie J, Race RW. Learning for organizational effectiveness: Philosophy of education and human resource development. Human Resource Development Quarterly 1998; 9(1): 54. https://doi.org/10.1002/hrdq.3920090105
[13] Encyclopedia of Educational Evolution. Ed. by Anderson SB, Ball S, Murfey R. San Francisco, 1975.

Received on 06-08-2020

Accepted on 31-08-2020

Published on 14-09-2020

DOI: https://doi.org/10.6000/2292-2598.2020.08.03.37

(C) 2020 Elmira et al.; Licensee Lifescience Global.

This is an open access article licensed under the terms of the Creative Commons Attribution Non-Commercial License (http://creativecommons.org/licenses/by-nc/3.0/) which permits unrestricted, non-commercial use, distribution and reproduction in any medium, provided the work is properly cited. 